\title{
EL PLAN MAESTRO DE LA HABANA VIEJA: CONTEXTO Y PROPUESTAS.
}

\author{
JUAN JOSÉ LÓPEZ CABRALES
}

\section{El encuentro}

Cada ciudad es un misterio. Un misterio que puede acabar enamorándonos (1), causándonos indiferencia e incluso determinándonos a marchar. Porque una ciudad nos muestra mucho más que su espacio, más que sus calles, que los edificios emblemáticos o anónimos que la adornan. A la ciudad, sobre todo, la conforma la gente que habita en ella. Y como cada persona encierra también su laberinto, el enigma se multiplica como el eco, por cada esquina, en cada habitación anónima.

En toda ciudad aparecerán miles de rostros ante nuestra mirada. Rostros humanos y rostros de piedra, unas veces amables, otras veces huraños. Estos centenares de miles de facetas acaban configurando, por una extraña agregación, la imagen que en cada uno se genera de la ciudad. Aunque este proceso se da tanto en la pequeña aldea como en la gran urbe, ésta última nos desafía más intensamente. Por su propia dimensión, nos pedirá un trabajo de síntesis más complejo y nos enseñará más de nosotros mismos. Adentrándose en el misterio de la urbe, el viajero ha terminado por adentrarse en el misterio de sus gentes y, por último, se ha visto empujado a la introspección para hallar en sí mismo claves con las que conocer la ciudad y mantenerse en ella.

Descubrir La Habana supone, sin duda, un reto excitante. Aunque se hablase a principios de siglo de la capital cubana como de la París del Caribe, no creo que esta singular ciudad tenga nada que envidiar a ninguna otra del mundo. En su estado actual, La Habana romperá completamente los 'esquemas del occidental que se interne por ella. Perderse por las calles de Centro Habana, de La Habana Vieja, dejar a un lado los recorridos turísticos al uso, supone vivir el contraste entre un presente desvencijado y un pasado de glorioso diseño, tropezar de bruces con el hacinamiento y la insalubridad en el marco de una vida que hierve imparable, quedar envuelto por el olor característico del gas, los que desprenden contenedores repletos de basuras y rodeados de nubes de moscas, o bien los perfumes exhalados por solares y derrumbes transformados por la desidia en vertederos. Y todo dominado por el calor, ese calor húmedo y dulzón, ese sudor que proviene de los adoquines cuando llueve, ese calor indolente que parece sumergir al caminante en un sueño a medio camino entre la pesadilla y el esperpento. Se trata, en resumidas cuentas, de vivencias muy diferentes a las que se pueden hallar en las urbes occidentales (2). En ellas, sin duda, existen también bolsas de pobreza pero, generalmente, nos encontraremos con una pobreza de puertas adentro, oculta tras fachadas presentables, o bien con una miseria localizada en lugares poco accesibles. Por eso, para el habitante de las ciudades 
europeas o norteamericanas, vivir la Habana equivale a percibir una forma muy especial de expresarse del espacio urbano y esta percepción exige a quien se halle interesado en el estudio de la ciudad una reflexión seria y consciente.

La imagen de la Habana como ciudad recuerda a uno de esos momentos inolvidables de la historia de la pintura: el Finis Gloriae Mundi de Valdés Leal. En dicha obra se muestran en primer término dos cadáveres exquisitos en descomposición, el de un caballero de Calatrava y el de un obispo, revestidos de lujosas mortajas y de gusanos. La Habana Vieja, por su imagen, por sus olores, aparece ante nuestros ojos como un organismo ayer espléndido y hoy putrefacto, pero en absoluto muerto. Como si, remedando las metáforas visuales de los surrealistas, alguien rebosante de vitalidad presentase el aspecto de un ruinoso despojo supurante. Por otra parte, quizá el Cádiz Viejo en el que transcurrió mi infancia -y muchas partes del de hoy-, con su miseria, sus partiditos y sus entresuelos, tuviese algo que ver con esa ciudad enferma pero apasionante y hermosa que pude admirar en una extraña regresión a los parajes transmutados de un tiempo perdido e inexistente.

Para contribuir, en la escasa medida de mis posibilidades, a difundir la necesidad imperiosa de colaboración que La Habana en particular y el pueblo cubano en general reclaman de ese mundo supuestamente «civilizado»-que no duda en afirmar su barbarie con aberraciones jurídicas como el texto de la Ley Helms-Burton-, decidí escribir estas líneas sobre un ambicioso proyecto que se encuentra en elaboración actualmente y que tiene la revitalización integral de La Habana Vieja como principal objetivo: El Plan Maestro.

Y como si los hechos quisieran encargarse de demostrar lo lejos que se hallan mundos que se deben tanto, España suspendía a mediados de 1996 la mayor parte de sus proyectos de cooperación con Cuba y cortaba, entre otras, sus valiosas aportaciones a este interesante plan de rehabilitación de una ciudad irrepetible y, por fortuna, aún conservada. La miopía de los políticos triunfaba nuevamente sobre los dictados de la razón y el sentido común, anteponiendo criterios partidistas a consideraciones de otra índole.

Antes de pasar a enunciar algunos de los aspectos más destacados de este Plan, tal como los conocí por conversaciones con diferentes personas adscritas al mismo y manejando parte de su voluminosa documentación, convendrá detenerse sobre algunas de las particularidades históricas de la zona a la que afecta: La Habana Vieja.

\section{Evolución de La Habana Vieja en el contexto de la ciudad.}

Al referirnos a La Habana Vieja, nos centramos en la zona del antiguo intramuros de la capital cubana, si bien el Plan Maestro incluye algunas manzanas adyacentes de la zona llamada Centro Habana. Siguiendo las concepciones defensivas propias de la Edad Media y de la Edad Moderna, La 
Habana se hallaba circundada por una muralla defensiva que recordaba la preeminencia del poder colonial y, a la vez, suponía un freno al crecimiento de la ciudad (3). Entre 1600 y 1750 aproximadamente, la ciudad se mantuvo dentro de los límites marcados por esa formidable línea defensiva. Luego los desbordó. Puede decirse, por tanto, que...

«La Habana era una ciudad dividida. Un concepto medieval de defensa la obligaba a adoptar un carácter más estático que el que exigían sus verdaderas necesidades: escapar de las murallas, ya obsoletas» (4).

En esa división, la zona de intramuros conservó siempre una dinámica diferencial propia, al residenciarse en su espacio las sedes principales del poder colonial, tanto el civil -plaza de armas y Capitanía- como el religioso -la catedral-. A la vez, la insuficiencia del espacio primitivo determinó hacia 1570 la expansión hacia el sur y la aparición de una plaza Nueva, llamada hoy paradójicamente plaza Vieja. La urbanización que se desarrolló a partir de esta área de crecimiento urbano supuso el primer ejemplo en América de la aplicación de las trascendentes ordenanzas de Poblaciones dictadas por Felipe II en 1573, puesto que su contenido debió de ser recogido en las ordenanzas municipales propuestas en 1574 por el oidor Alonso de Cáceres (5), ordenanzas cuya primera aplicación reguló la expansión de esta zona de plaza Vieja y que mantuvieron su vigencia un largo periodo de tiempo.

Rodeada por tanto de murallas, fortificaciones y castillos -el Morro y la Cabaña, perfectamente divisables desde la avenida del Puerto, y la Punta y la Real Fuerza, en la misma orilla de la bahía-, La Habana Vieja podía dar la impresión de una ciudad reprimida o encorsetada y, sin embargo...

«Detrás de aquellos muros formidables y entristecedores aparecía un mundo de colores y de alegría. Una caleidoscópica yuxtaposición de razas y matices étnicos, de etapas históricas, en suma, y de riquezas y miserias constituía la faz de aquella capital donde el extranjero ya encontraba todo lo que había dejado en su país, más las diversiones y los vicios universales que daban a la vida habanera su permanente mala fama» (6).

Ese mundo vibrante que escondían los muros también se fue reflejando en un estilo arquitectónico recargado y de un eclecticismo barroquizante que se ajustaba a las características vitales de la parte vieja de la ciudad, diferenciándola de otros centros históricos americanos. Así lo percibió Alejo Carpentier cuando escribió lo siguiente:

«(...) poco a poco, de lo abigarrado, de lo entremezclado, de lo encajado entre realidades distintas, han ido surgiendo las constantes de un empaque general que distingue La Habana de otras ciudades del continente» (7). 
Eclosionan, en suma, una serie de rasgos y tipologías que se van desarrollando hasta la actualidad pero que encuentran su origen en los principios mismos de la ciudad.

Tras esa primera expansión del XVII y tras aparecer los elementos de una fisonomía propia, el siglo XVIII supone un momento de máximo crecimiento urbano para La Habana. Fue entonces cuando el recinto de intramuros quedó completo, siendo reconstruidas muchas viviendas para la burguesía adinerada, y cuando la gente más humilde

«(...) se vio obligada a establecerse fuera de las murallas, dejando delante de ellas grandes descampados exigidos por las leyes militares. Se comenzaron a formar los grandes barrios extramurales (...)» (8).

El estilo arquitectónico en el que se expresó esta fiebre edificatoria fue el barroco pero, quizá a despecho de las opiniones de Carpentier acerca del barroquismo consustancial a lo habanero, también existe una impronta neoclásica significativa en la parte vieja de la ciudad. Este neoclasicismo floreció durante el siglo XIX y del mismo queda como vestigio más significativo el Templete, junto a la plaza de Armas que,

«(...) dada su céntrica ubicación, su significación histórica y la novedad de su pulcro orden Dórico, debió de ejercer una decisiva influencia en impulsar el Neoclasicismo en Cuba» (9).

Lo cierto fue que, más que en el centro antiguo, el nuevo estilo clásico triunfó en las obras realizadas tras el que sin duda constituyó el principal acontecimiento urbanístico de la capital cubana durante el siglo XIX: la demolición y reparto de las murallas de la ciudad. Esta reestructuración de la fisonomía de La Habana se enmarcó en las operaciones que se habían llevado a cabo en las principales ciudades europeas y españolas del momento privadas igualmente de sus murallas: recuérdense, entre otras intervenciones, el Plan Castro en Madrid, la actuación de Cerdá en Barcelona y, sobre todo, la remodelación emblemática de París dirigida por el barón Haussmann. En definitiva...

«La experiencia urbanística mundial también alentaba el proyectado derribo (...). Fueron los años del nacimiento del urbanismo moderno, y la prensa local comentaba muchas de estas nuevas empresas» (10).

Desde finales de los años sesenta del siglo XIX se produjo, por fin, la necesaria unión entre la nueva y la vieja Habana. Esta unión dejó una suturación claramente visible en el eje que, siguiendo el trazado de las antiguas fortificaciones, une actualmente Fundición y la plaza de Máximo Gómez. En esta zona de fusión de dos mundos secularmente separados se erigieron construcciones de una importancia emblemática. La Estación Central de Ferrocarriles, por una parte, que simbolizó la irrupción de una nueva realidad 
industrial y, por otra, dos edificios esenciales desde un punto de vista político: el palacio Aldama -hoy museo de la Revolución- y el antiguo Capitolio, que se convirtieron en las señas de identidad de un poder diferente. Todos estas realizaciones fueron, en suma, las obras de una oligarquía lo suficientemente poderosa como para adquirir terrenos con una centralidad que elevaba enormemente sus precios y cuyos miembros necesitaban, en el plano ideológico,

«(...) mostrarse como agentes del progreso, un progreso capaz de asimilarse a esos adelantos técnicos e industriales que los convertían en poderosos monopolizadores de la riqueza insular. (...) Esta tendencia, que se desplegaba en el último tercio del siglo teñida de un fuerte matiz dependiente, dejó sentadas las bases de una transición sin violencia hacia la arquitectura republicana. No será hasta entonces que se generalizará la construcción de caracteres ajenos a la tradición colonial (...)» (11).

La transformación sufrida por la capital cubana tuvo su momento de mayor intensidad entre el establecimiento de la República -1902- y el comienzo de la crisis económica de 1921 y afectó tanto a la zona central, eje de nuestro estudio, como a los barrios colindantes. El cambio asombró a los que lo contemplaron, que los describieron sin disimular su admiración:

«En poco más de quince años la Habana se ha transformado por completo (...) ha roto sus antiguas lindes. Sus nuevas barriadas llenas de chalets y palacetes elegantísimos la han hermoseado (...) en las calles céntricas el movimiento se concentra y precipita como una catarata» (12).

A pesar de esta fiebre edificatoria, muchas zonas de La Habana Vieja continuaron presentando los problemas de sobreutilización y falta de higiene que actualmente siguen resultando tan preocupantes y que motivaron en su día la protesta de arquitectos, higienistas e intelectuales en general. Éstos, recogiendo ideas ya formuladas en Europa, representan el inicio de una auténtica conciencia urbanística sobre La Habana. Hombres como Ramón Zambrana y Ramón Meza alzaron ya en el siglo XIX su voz para criticar la configuración urbanística de la zona intramural. En 1924 el arquitecto Luis Bay Sevilla publicó su conocido libro Vivienda del pobre (13) y diez años antes, en el Congreso Obrero de 1914, se

«(...) denunciaron las condiciones de extrema inhabitabilidad de las casas de inquilinato, los solares y las ciudadelas que abundaban en La Habana Vieja y se extendían por los barrios antiguos de extramuros» (14).

En general, puede decirse que al capital no le preocupaba más que una pronta realización de beneficios y, en ese sentido, Llanes reduce a cinco los aspectos esenciales de la actividad edificatoria de principios del siglo XX:

«(...) el predominio de la iniciativa privada sobre la estatal, la ausencia de un plan científico de urbanización, la especulación urbana, la violación de las 
reglamentaciones vigentes y la ausencia de interés por solucionar los problemas del proletariado (...)» (15).

Estas características se mantendrían hasta el triunfo de la Revolución en 1959 y produjeron una degradación de la residencia en el centro histórico. Junto a la falta de higiene, la aparición de edificios de excesiva altura fue otro inconveniente que tuvo que afrontar La Habana Vieja durante la etapa republicana. La revista Arquitectura, en su número de Octubre de 1918 así lo denunciaba:

«La construcción de rascacielos cuya altura resulta desproporcionada en relación con la anchura peculiar de las calles más céntricas de nuestra urbe, lejos de refrescar el ambiente tiende a enrarecer la atmósfera y oscurecer las calles (...)» $(16)$.

Una consideración de algunos datos cuantitativos pone de relieve la enorme transformación de la ciudad en la etapa prerrevolucionaria. Partiendo de los 4 $\mathrm{Km} 2$ que tendría La Habana durante la mayor parte del siglo XIX, se pasa a 95 en 1919, calculando el censo de ese año un total de 432.353 habitantes. En 1923 la superficie alcanzaba los $116 \mathrm{~km} 2$ y $200 \mathrm{~km} 2$ en 1959 . Seis años antes, la población de La Habana había llegado al millón de habitantes. Son los años comprendidos entre 1919-1931 los que marcan el inicio de la explosión demográfica. La explicación la encontramos en la grave crisis económica que sufre la República a principios de los años veinte y que prácticamente enlaza con las secuelas de la crisis de 1929. Esta crisis determina una ciudad que

«(..) aprovechará más que cualquiera otra ciudad el desarrollo industrial y comercial que la propia crisis induce y asimilará una gran población que huye del campo azotado por la miseria.» (17).

Todo ello acentúa la ruina y la saturación de las viviendas de La Habana Vieja y, ante esta situación, se produce una transformación radical de la realidad socioeconómica de la zona. En poco tiempo

«(...) la aristocracia tradicional y la alta burguesía emigran hacia el Vedado (...). La tipología arquitectónica que caracteriza los suburbios burgueses en las primeras décadas de este siglo no tiene relación alguna con la unidad estilística conservada a lo largo del siglo XIX» (18).

La Habana Vieja, sin perder el carácter solemne de muchas de sus edificaciones -con todo el prestigio simbólico que esto implicaba-, se convirtió entonces en el

«(...) centro comercial de una parte de la pequeña burguesía y de las clases populares y asiento de almacenes y talleres, causa principal ésta última del deterioro y la contaminación que determinaron por depreciar este territorio, caracterizado además por sus altas densidades poblacionales» (19). 
A estos problemas, existentes tanto en La Habana Vieja como en muchos puntos del resto de la capital y de la mayor parte de las ciudades cubanas, opuso la etapa política que se inicia en 1959 una actuación basada en la construcción de viviendas y en los Planes Directores de la ciudad. En el primer aspecto, en el período comprendido entre 1959 y 1980 se edificaron en La Habana 55.000 viviendas pero, por una parte,

«(...) podemos decir que en la inmensa mayoría de nuestras urbanizaciones posrevolucionarias se subutilizó el suelo al atentar contra los más elementales principios de la economía urbana; $m 2$ de vías de redes de área urbanizable, extensión de las ciudades con el consiguiente gasto de transporte, etcétera» (20)

y, por otra, el hecho de que la ciudad duplicase su población alcanzando los dos millones de habitantes a finales de los ochenta -recordemos' que había llegado al millón a mediados de los cincuenta-, hicieron claramente insuficiente este afán edificatorio. De todas formas, no puede negarse que la Ley de Reforma Urbana de 1.960 aliviaría al menos la dañina presión especuladora y estimularía la construcción por parte de los vecinos (21).

En cuanto a los planes directores, hubo uno de 1968, con una investigación preliminar de la Comisión de Monumentos sobre La Habana Vieja que determinó las construcciones dignas de restaurarse y, después, un nuevo Plan Director en 1970, actualizado con un Inventario urbano general en 1975/76. El Plan del 70 trataba de asegurar la articulación de La Habana Vieja con el resto de la ciudad y la multiplicidad de funciones de la zona. Así se evitaría

«(...) la conversión de La Habana Vieja en barrio-museo, garantizando la permanencia de la función residencial y el desarrollo de nuevas actividades (turísticas, culturales, educativas, artesanales, etc.). La demolición de toda construcción en mal estado y sin valor histórico abrirá amplias brechas haciendo penetrar el paisaje colonial del puerto dentro de La Habana Vieja, permitiendo la continuidad entre ciertos elementos antiguos (calles estrechas, patios interiores, etc.) y otros nuevos (parques, caminos, los nuevos edificios de viviendas)» (22).

Esta tendencia a la demolición se sustituye en el Inventario -en el que apenas se relacionan edificaciones perjudiciales para el valor histórico de las edificaciones del núcleo original- por una

«(...) política cuidadosa de restauración, revitalización y uso de las nuerosas edificaciones y espacios abiertos subsistentes (plazas y plazoletas), pues no es recomendable eliminarlas sin más como si se desease borrar de raiz la historia urbanística de la ciudad» (23). 
Esta es la tendencia que se recoge en la Ley de Protección del Patrimonio Cultural de 1977, el Reglamento sobre Planificación Física de 1978, en el Plan Director -1980/2000- y ahora en el Plan Maestro.

Y no puede ser de otra manera porque, como acertadamente nos recuerda el arquitecto Oscar R. Hernández, no debe olvidarse una exigencia impuesta por la austeridad:

«Ninguna economía, por alto que sea su nivel de desarrollo, puede despreciar el valor de los fondos básicos existentes, ni siquiera en el supuesto caso de que en estos no se encontraran valores culturales algunos» (24).

Mucho menos puede permitirse ese lujo una nación como Cuba, que atraviesa una delicadísima situación económica y que tiene en La Habana Vieja un centro de incalculable valor monumental y cultural, lo que determinó su declaración por la UNESCO como Patrimonio de la Humanidad en 1982.

A pesar de estas consideraciones de partida sumamente válidas y de las intachables intervenciones rehabilitadoras que se han desarrollado en puntos aislados de La Habana Vieja muchas zonas del núcleo de la capital cubana sufren un deterioro lamentable y peligroso (25). Podemos coincidir con Daniel Taboada cuando afirma que el centro histórico de La Habana

«(...) es un organismo vivo con todos sus defectos y virtudes, un organismo enfermo pero vivo, marcado por la huella del hombre y su expresión constructiva a través de diferentes épocas cada una con características disímiles hasta el día de hoy» (26).

Hasta aquí el resumen de la evolución urbana de la capital de Cuba. Considerando que muchos de sus problemas toman dimensiones parecidas en otras ciudades del continente, no resultará ocioso esbozar una breve reflexión sobre los rasgos comunes de los centros históricos sudamericanos. Concluiremos, posteriormente, con el apunte de algunas de las principales propuestas que contienen los trabajos de preparación del Plan Maestro.

\section{La situación de los centros históricos en Latinoamérica.}

Antes de abordar un tema tan complejo como éste, creo conveniente mirar atrás y rebuscar en el pensamiento de quien ya es en cierto modo un clásico en la materia, Pier Luigi Cervellati, para tratar de encontrar un punto hacia el que encaminar la reflexión. Desde su punto de vista...

«El centro histórico representa el lugar privilegiado para insertar la batalla por el derecho a la casa y a la ciudad, para interrumpir la continuidad de la crisis urbana generada por el uso impropio y por la explotación anticultural y antisocial de la ciudad del pasado (...). Conservar el centro histórico significa sobre todo proyectar o reconstruir la relación estable entre población y 
actividades humanas y el organismo antiguo concebido con su significado más amplio de escenario físico» (27).

Estas palabras, alumbradas en el contexto europeo, encierran una valiosa idea de futuro aplicable también al caso latinoamericano. No obstante es preciso recuperar las coordenadas propias de la realidad de Sur y Centroamérica para captar el mensaje en su verdadera dimensión.

En ese sentido hay que anotar cómo el crecimiento desarticulado de las economías latinoamericanas y su dependencia del capitalismo desarrollista tiene repercusiones nefastas sobre las grandes ciudades a partir de los años cincuenta. Se acelera entonces: la separación entre una zona antigua -casco histórico-, en el que hasta ese momento se hallaba el núcleo representativo del Estado, y el resto del tejido urbano, sometido a un crecimiento fuera de control por efecto de la especulación. También el centro va a sufrir esas tensiones pero, en general, por su menor adaptabilidad a las necesidades de expansión y crecimiento que impone el sistema económico, quedará progresivamente relegado a funciones de residencia precaria. Sin embargo, existen casos lamentables, como el de Caracas, en los que la imposición a la fuerza sobre la trama del casco antiguo de las exigencias del desarrollismo han provocado la desaparición casi completa del centro histórico como tal.

Sin embargo esta ciudad nueva, hija de un concepto de «progreso» que se aproxima más bien al de destrucción y muerte, ha fracasado, entre otras cosas porque el desarrollismo económico

«(..) no ha conseguido ciudades mejores ni ciudadanos más felices, y ha hecho volver los ojos de la sociedad sobre sus propias raíces» (28).

En nuestra mirada hacia un pasado que puede encerrar algunas claves válidas para una construcción reactualizada del futuro, resulta esencial saber captar algunas diferencias que separan las ciudades históricas iberoamericanas de las del resto del mundo. Hay que tomar en consideración, por tanto, que...

«En las grandes ciudades latinoamericanas se ha producido, desde hace un siglo aproximadamente un progresivo abandono de los centros urbanos; (...) la oligarquía y la burguesía rica se desplazaron hacia suburbios confortables (...). El decaimiento y deterioro del centro histórico ha generado el hacinamiento, la promiscuidad y la «tugurización»; al mismo tiempo, ha contribuido a la decadencia física del centro" (29).

Sobran los comentarios ante las similitudes de esta afirmación genérica de Gasparini, aplicable a la mayor parte de las ciudades iberoamericanas, y el caso ya analizado de La Habana Vieja. Pero no pueden pasarse por alto las graves desventajas que representa para las clases populares este tipo de ocupación 
«(...) debido a que la familia debe soportar altos costos de alquileres, el riesgo de transitorialidad (sic) en el área de tugurización, carencia del arreglo o mantenimiento de las viviendas y de los servicios por parte de los propietarios, deficiencia de servicios públicos (...)» (30).

Me interesa considerar ahora otra característica que, aunque ha sido menos frecuente en Cuba por la propia dinámica política de esta nación, ha revestido cierta importancia en Latinoamérica: la aparición de movimientos sociales urbanos. En ellos, los estratos más bajos de la población, diferenciados por intereses grupales y tradiciones culturales diversas,

«(...) son homogeneizados al nivel de las contradicciónes urbanas» (31).

Aunque los movimientos sociales urbanos en Europa Occidental han perdido buena parte de la fuerza que tuvieron a finales de los años setenta y en los ochenta, el agravamiento de esas contradicciones urbanas en América Latina debería intensificar y cohesionar la protesta vecinal. La ciudad no es de sus autoridades sino de quienes las habitan. El único sentido de la acción de los gobernantes es lograr el bienestar de los ciudadanos y, por eso mismo, son los que viven la ciudad y sus incomodidades quienes más deben luchar en la obtención de un ámbito digno de vida. A mi modo de ver, esta batalla tendría que encauzarse a través de un diálogo permanente y constructivo con las autoridades competentes en la gestión de la ciudad. Y son los que residen en el centro histórico, en contacto permanente con ese espacio pretérito en el que reside el núcleo del significado y la conciencia de cada urbe, los que quizá se hallen llamados a estimular este diálogo. No basta con delegar las exigencias y necesidades en un poder paternalista y previsor que solucione todos los males. Lo más importante es reorganizar la ciudad a la medida de quien la vive. Y para ello resulta previo y preciso, entre todos, construir una ética de la ciudad,

«(...) hacer más conciencia en las personas y en los centros de trabajo de que no pueden servirse de la ciudad como un Neandertal contemporáneo (...). Hay gente que usa la ciudad como si fuera un bien despreciable; y se está destruyendo, se está rompiendo la capacidad de autorrecuperación de la ciudad, porque (...) llega un momento en que (la ciudad) ya está al límite de saturación, por deformaciones donde ya no se puede dar marcha atrás (...)» (32).

Los urbanistas, los arquitectos, los políticos encargados del gobierno de la municipalidad son los principales responsables de que se genere esa ética en los ciudadanos (33) y de crear ciudadanos críticos, capaces de aunar sus intereses y, con inteligencia y flexibilidad, exponer las necesidades y las soluciones que exige la ciudad americana del siglo XXI. En esta ciudad, el centro histórico tendrá que ser mucho más que un museo y, por eso mismo, el objetivo esencial de las intervenciones no puede ser atraer al turismo, ajeno por su propia naturaleza a la identidad de la ciudad. No se trata, desde luego, de criticar sin más el turismo: Por una parte, el turista puede integrarse con interés y respeto en el devenir natural de la ciudad y, por otra, los paises menos desarrollados necesitan 
los ingresos del turismo para apuntalar sus economías y generar recursos que les permitan, entre otras cosas, garantizar la salvaguardia material y espiritual de su patrimonio. Pero, aún reconociendo esta realidad,

«(..) las formas de puesta en práctica y de control de los efectos del turismo demandan estudios sumamente cuidadosos y pormenorizados» (34)...

...para evitar una agresión irreversible que, como efecto perverso, produzca la muerte de aquello que se pretendía salvar. Por eso, en una ciudad histórica integrada, el patrimonio social habrá de respetarse tanto o más que el históricoartístico para lograr un espacio vivo y en desarrollo, todo lo contrario a ese downtown en frenética actividad financiera -turística en este caso- por las mañanas y muerto cuando las oficinas - o museos- cierran sus puertas. Porque lo que atrae al visitante es la vida y no la muerte, el objetivo de la revitalización de las ciudades históricas se alejará de una mera vuelta al pasado

«(..) donde el pasado se hace más importante que el presente, donde el pasado sirve, no para enseñar, sino sólo para justificar nuestras decisiones. (...) Quizás sería necesario pensar en la historia como una útil pero irrepetible lección, llena de belleza. Quizás haría falta poner al día la modificazione: un programa no con el que explicar el pasado, sino con el que entrever el futuro» (35).

En esa línea, a mi juicio, han de moverse las actuaciones en los centros históricos en general y en los de las economías dependientes en particular. Por los datos que he podido reunir, el Plan Maestro de La Habana Vieja ha centrado en esa filosofía buena parte de sus premisas. Pasemos a considerar algunos de sus principales objetivos como conclusión de este trabajo.

\section{EI Plan Maestro de La Habana Vieja: punto de partida.}

No hallándome adscrito de ninguna manera a las instituciones que colaboran en la elaboración del Plan Maestro de la Habana Vieja, y no encontrándose éste más que en proceso de elaboración, la información que voy a adelantar sobre este interesante proyecto procede esencialmente de una entrevista que mantuve en Julio de 1996 con D. Francisco Volta, coordinador jurídico del Plan, y de la documentación y planimetría que éste tuvo la amabilidad de facilitarme. Aunque mi visión no sea, por tanto, profunda ni interna, pienso que la propia importancia del documento que vamos a considerar -que afecta al centro histórico mejor conservado entre los de las capitales de América Latina- justifica el intento de difusión del mismo que supone este artículo.

Hay que resaltar en principio la multidisciplinariedad de la oficina técnica de profesionales que se hallan trabajando en la elaboración del Plan Maestro: arquitectos, ingenieros, geógrafos, historiadores del Arte, sociólogos, topógrafos; abogados..., todos tienen algo que decir y todos están colaborando 
en la producción de una imagen lo más comprensiva posible de La Habana Vieja. Se trata con ello de facilitar una intervención eficaz sobre un tejido social y culturalmente tan delicado. Resulta a la vez extensísima la nómina de entidades que colaboran con el Plan -Asamblea provincial del Poder Popular de la Ciudad de La Habana, Asamblea municipal del Poder Popular de La Habana Vieja, Centro Nacional de Conservación Restauración y Museología, Instituto de Planificación Física, Facultad de Arquitectura de La Habana, Dirección municipal de Arquitectura y Urbanismo de La Habana Vieja, Policía Nacional de Tránsito, Empresa del Gas Manufacturado, Archivo Nacional de Cuba, Oficina Nacional de Estadística, Dirección Municipal de la Vivienda de la Habana Vieja, hasta sumar un total de 28-, todas coordinadas por la Oficina del Historiador de la Ciudad de La Habana e, inicialmente, por la Agencia Española de Cooperación Internacional, que ya había participado en la revitalización de centros históricos de otras naciones iberoamericanas y aportaba, por tanto, una valiosa experiencia al caso cubano (36) de la que se ha tenido que prescindir tras la retirada del apoyo español por decisión del gobierno de la derecha. A pesar de esta extensa nómina de instituciones colaboradoras, el personal cualificado estable con el que cuenta la oficina técnica del plan no supera los veinte profesionales, siendo mucho más numeroso los colaboradores eventuales y el personal administrativo.

La situación institucional peculiar que ocupa la Oficina del Historiador de la Ciudad de La Habana, determina también la preeminencia del Plan Maestro. Hasta hace tres años la Oficina fue una simple entidad del Ministerio de Cultura, pero mediante el Decreto Ley 143/30-X-93 se transforma en un organismo autónomo, con funciones propias, dependiente del Consejo de Estado, organo supremo en el esquema de gobierno cubano.

Las labores que se fija el Plan Maestro son tres:

-Una primera etapa de diagnóstico, que es en la que se hallan actualmente Agosto de 1996- los trabajos de ejecución del Plan, en la que se recogerá toda la información necesaria, se elaborarán planos y mapas y se analizará en profundidad la situación del área de estudio. Una de las tareas más importantes, que ya se ha realizado en estos momentos, es la distribución funcional de las zonas de La Habana Vieja y alrededores objeto de estudio (ver Plano adjunto). Se establecen tres sectores relacionados con el turismo. $\mathrm{T} 1$, zona esencial desde el punto de vista histórico artístico y que, partiendo desde las inmediaciones de la Plaza Vieja, incluye los elementos emblemáticos más significativos monumentalmente del centro histórico de La Habana -Plaza de Armas, Catedral, Castillo de la Real Fuerza, S. Francisco-, conectando en la Plaza de Máximo Gómez con T3, área que abarca todo el norte de la antigua muralla, y que incluye edificios más recientes que los de T2 pero tan significativos como el antiguo Capitolio, Gran Teatro, Palacio Adama -museo de la Revolución- y una gran cantidad de zonas verdes -Parque de la Fraternidad, Parque Central y el Prado.T1 y T3 se comunican a través de una línea de unión entre el Capitolio y la Plaza de Armas que generaría la zona llamada $\mathrm{T} 2$, en torno a dos arterias esenciales en 
La Habana Vieja como son las calles Obispo y O'Reilly. Por otra parte, en los extremos norte y sur de La Habana Vieja propiamente dicha se sitúan dos zonas con funciones estrictamente de vivienda, $\mathrm{R} 1$ y $\mathrm{R} 2$. Al norte de $\mathrm{R} 2$, tomando como límites las calles Obrapía al norte y Muralla al Sur, se define una zona de vivienda permisiva o MR. Sobre la estación Central de Ferrocarriles se delinea una tercera zona residencial, R3. Todo este esquema zonificador concluye con una franja situada esencialmente alrededor de la línea marcada por las avenidas de Bélgica y de las Misiones, continuando al Sur por Desamparados y San Pedro, y que se concibe como un sector mixto, $M$. Tenemos, por tanto, tres sectores relacionados con el turismo-T1, T2, T3-, tres sectores de vivienda estricta-M1, M2, M3-, un sector de vivienda permisiva -MR- y rodeando buena parte del barrio de La Habana Vieja una franja que constituye el sector mixto-M-. Esta distribución funcional y espacial, compleja en la explicación verbal pero mucho más fácil de comprender y coherente si se examina sobre el plano, no surge como un reparto caprichoso: se trata del resultado de todos los trabajos de prediagnóstico y ha servido de base para encauzar la labor posterior del Plan, constituyendo el núcleo de la proyección del futuro que se quiere para el casco antiguo de La Habana. Se opera sobre ella en un sofisticado soporte informático que va a constituir el esquema sobre el que se irá incorporando toda la información que se recoja de cada manzana, cada cuadra, inmueble, domicilio, habitante..., tanto a un nivel arquitectónico como sociolaboral. Este trabajo cristalizará cuando, en coordinación con la Ofícina Nacional de Estadísticas, se elabore un Censo de Población y Viviendas del área.

-En un segundo momento se redactaría el Plan Maestro de la Habana Vieja y se llevarían a cabo actuaciones concretas para implementar las acciones más urgentes. Podríamos destacar algunas de las previstas: Primero, asegurar las condiciones de seguridad y salubridad de las viviendas, edificios y espacios interiores y exteriores de la zona de estudio-rehabilitando y consolidando los edificios y construyendo nuevas viviendas en los solares existentes- y perfeccionar los servicios para uso de la población residente. El objetivo sería lograr que en La Habana Vieja se mantuviese un uso esencialmente residencial, evitando tanto como fuese posible el desplazamiento de sus habitantes a otras partes de la ciudad. Entre las operaciones más destacables en este orden de cosas, destacaría la necesidad de evitar la proliferación de las barbacoas en las viviendas. Éstas consisten en divisiones de los altos techos de las casas coloniales antiguas mediante estructuras realizadas con materiales poco sólidos y sin supervisión técnica alguna. Se vienen realizando desde hace varias décadas, como resultado de la presión de una población en aumento y con recursos económicos muy escasos. En otras ciudades de las economías dependientes esta situación da lugar a la aparición de cinturones de miseria en torno a las grandes urbes. La política restrictiva en este sentido aplicada por el Estado cubano, que practicamente ha erradicado el problema del chabolismo, no ha podido evitar sin embargo estas barbacoas. Según el Plan Maestro habrán de ser eliminadas, salvo las realizadas con materiales sólidos y que ofrezcan garantías de permanencia -en este caso reciben el nombre de mesaninis o entresuelos-. Segundo, elaborar una propuesta para el tráfico rodado, en 
colaboración con el Instituto de Investigaciones del Transporte: pretender peatonalizar totalmente una zona tan extensa y con una actividad tan rica como La Habana Vieja no sería realista, pero hay que tener en cuenta que la mayor parte de los edificios carecen de cimientos y que los efectos perniciosos del tráfico pesado sobre sus estructuras se traducen con frecuencia en derrumbes y ruinas. Por tanto, establecer una política disuasoria del uso de los vehículos que estableciese, además, topes de tonelaje para la circulación por La Habana Vieja resultaría sumamente deseable. También debieran evitarse las actividades industriales que atraen el tráfico pesado como, por ejemplo, los almacenes de organismos oficiales que abundan en toda la calle Muralla. Tercero, aumentar el volumen de zonas verdes, utilizando para ello parte de los solares. Etc...

Para que estos y muchos otros problemas puedan ser resueltos con eficacia resulta absolutamente precisa una compleja labor de redacción jurídica que tropieza con un obstáculo importante: Cuba carece por ahora de una ley del suelo que regule los instrumentos de planificación, los tipos de suelo, sus usos, las infracciones y sus sanciones, etc. Las pocas normas urbanísticas que existen para La Habana son ordenanzas municipales que, con una mera actualización de 1963, derivan directamente de las existentes en los tiempos de la dominación española y que, quizá por su propia obsolescencia, se infringen o ignoran sistemáticamente. Sí se dispone en Cuba, como ya se ha apuntado, de una legislación de la vivienda y en defensa del Patrimonio Histórico que deberá ser coordinada con una futura Ley del Suelo que se halla actualmente en proceso de elaboración. Tampoco puede soslayarse otro desafío tan esencial como la puesta a punto de un Registro de la Propiedad, desde la base del Censo de Población y Vivienda al que ya se ha aludido, y que sirva para definir la situación de cada usuario.

-Resueltos estos retos podrá pasarse a una tercera fase, conclusiva, en la que se controlará y evaluará todo el trabajo realizado, actualizándolo desde unas premisas centradas en la crítica y la autocrítica.

Desde estas premisas podrá contribuirse a crear una Habana Vieja mejor que sirva de espejo en el que el resto de la ciudad y de la nación pueda mirarse para su propio perfeccionamiento. Quizás la forma más adecuada de concluir mi modesta aportación -la de un extranjero deslumbrado tras una breve estancia en la ciudad- a esta tarea apasionante, sea escuchar la opinión de Mario Coyula, gran profesional y hombre comprometido con esa ciudad en peligro que es La Habana, a la que el Plan Maestro puede contribuir a salvar:

«A veces uno oye hablar de transformar La Habana y yo me pregunto ¿por qué transformarla si es bonita? Vamos a recuperarla, a rehabilitarla. Debemos hacer que funcione lo que dejó de funcionar, reparar lo que se ha deteriorado, recuperar lo bueno que se perdió y sea racionalmente recuperable; e insertar con cuidado dentro de esa trama, mixtura de todas la épocas, obras nuevas que la realcen, que interpreten creadoramente en términso contemporáneos lo válido 
del pasado dejando, casi sin quererlo, la huella de este tiempo difícil y hermoso» (37).

\section{NOTAS}

(1) Lo cierto es que resulta cada vez más difícil escribir poemas de amor a las ciudades, sobre todo a las grandes urbes emblemáticas, porque la vida en ellas se va haciendo con el tiempo más incómoda, solitaria, insolidaria y monótona. Uno de los autores que quizá ha puesto más corazón en sus escritos sobre la ciudad es CALVINO, Italo: Las ciudades invisibles. MADRID, Eds. Siruela, 1994. En la nota preliminar al caleidoscopio de impresiones poéticas que conforman su libro, el autor reflexiona agudamente sobre la cuestión urbana: «Tal vez estamos acercándonos a un momento de crisis de la vida urbana y Las ciudades invisibles son un sueño que nace del corazón de las ciudades invivibles. (...) La crisis de la ciudad demasiado grande es la otra cara de la crisis de la naturaleza». -pag. 15-.

(2) Castells nos recuerda que «(...) el contenido de las formas urbanas que se están creando en América Latina es extremadamente diferente de la urbanización europea o norteamericana operada en las décadas precedentes (...) por la situaçión de dependencia en que las sociedades latinoamericanas siempre se han encontrado en el seno de un modo de producción capitalista que, desde su. nacimiento histórico, se ha estructurado a escala mundial». CASTELLS, Manuel: Crisis urbana y cambio social. MADRID, Ed. Siglo XXI, 1981, pag. 107.

(3) Sobre las murallas de la Habana y su significado funcional y simbólico, ver AA.VV: Transformación urbana en Cuba: La Habana. BARCELONA, Ed. Gustavo Gili, 1974, pp. 11/13, LE RIVEREND, Julio: La Habana, espacio y vida. MADRID, Fundación Mapfre, 1992, pp. 66/70 y 72/75 y BLANES, Tamara: «Las fortificaciones coloniales de la ciudad de La Habana». Arquitectura/Cuba. LA HABANA, No 370/1988, pp. 55/61. En cuanto a la reutilización de estos elementos en la ciudad actual, véase DIAZ, Salvador: «Rehabilitación de fortificaciones. Valor histórico, contexto y marco natural». Arquitectura/Cuba. LA HABANA, N 369/1987, pp. 37/43.

(4) CHATELOIN, Felicia: La Habana de Tacón. LA HABANA, Ed. Letras Cubanas, 1989, pag. 22.

(5) Una de las principales repercusiones de este deseo de organizar el crecimiento de la ciudad fue la extensión del trazado hipodámico u ortogonal. Al respecto puede consultarse: AGUILERA, Javier: «La cuadrícula: un modelo urbano para las ciudades americanas» Ciudad y Territorio, MADRID, $\mathrm{N}^{\circ} 54$, 1982 , pp. 55/77. También revistió un gran interés para profundizar en esa tendencia que se registra en las ciudades americanas en general la exposición organizada por el Centro de Estudios Históricos de Obras Públicas y Urbanismo 
y dirigida por Fernando de Terán bajo el título: La ciudad hispanoamericana. El sueño de un orden. Sus contenidos se recogieron en un grueso volumen bajo el mismo título publicado en Madrid por el M.O.P.U. en 1989. Sobre las ordenanzas municipales de Alonso de Cáceres nos dice LE RIVEREND, J: La Habana, espacio..., pag. 58, que en ellas «se regulaba la ya tradicional concesión de mercedes en tierras -semillero de pleitos- de solares, de arreglo de calles y ornato urbano que correspondían a una urbe de imperial importancia». Ignoro si existe un estudio en profundidad de las mismas, pero su análisis riguroso resultaría esencial para una historia de La Habana enfocada desde el punto de vista urbanístico.

(6) LE RIVEREND, Julio: La Habana (Biografia de una provincia). LA HABANA, Academia de la Historia de Cuba, Imprenta «El Siglo XX», 1960, pag. 316. Además de la otra obra sobre la Habana del mismo autor, otra síntesis acertada sobre la capital cubana se halla en el libro de VENEGAS, Carlos; NUÑEZ, Antonio: La Habana. MADRID, Eds. Cultura Hispánica, 1986.

(7) CARPENTIER, Alejo: «La ciudad de las columnas» en Tientos y Diferencias. LA HABANA, Eds. Unión, 1966, pag. 52. En la misma página nos recuerda el escritor que «(...) la superposición de estilos, la innovación de estilos, buenos y malos, más malos que buenos, fueron creando a La Habana ese `estilo sin estilo' que a la larga, por el proceso de simbiosis, de amalgama, se erige un un barroquismo peculiar que hace las veces de estilo, inscribiéndose en la historia de los comportamientos urbanísticos».

(8) SANCHEZ AGUSTI, María: Edificios públicos de La Habana en el siglo XVIII. VALLADOLID, Universidad, 1984, pag. 21.

(9) Esta es la opinión expresada por WEISS, Joaquín: La arquitectura cubana del siglo XIX. LA HABANA, Ed. Pueblo y Educación, 1989 (2), pag. XII.

(10) VENEGAS, Carlos: La urbanización de las murallas: dependencia y modernidad. LA HABANA, Ed. Letras Cubanas, 1990, pp. 38/39.

(11) VENEGAS, C: Op. cit., pag. 49.

(12) GONZALEZ, Francisco: Un canario en Cuba. LA HABANA, Imp. La Prueba, 1916, cit. en LLANES, Llilian: 1898-1921: La transformación de La Habana a través de la arquitectura. LA HABANA, Ed. Letras Cubanas, 1993, pag. 92 .

(13) Cit. por LE RIVEREND, J: La Habana, espacio..., pag. 256.

(14) LE RIVEREND, Op. cit., pag. 223.

(15) LLANES, L: 1898..., pag. 113. 
(16) LLANES, L: Op. cit, pag. 224.

(17) LE RIVEREND, J: La Habana (Biografia...), pag. 478/79

(18) AA.VV: Transformación urbana..., pp. 50/51. Sobre las tendencias de la arquitectura cubana de nuestro siglo, un valioso resumen es el de SEGRE, Roberto: «Nostalgia, renovación e identidad en la arquitectura cubana del siglo XX». Temas. LA HABANA, Nº 17, 1989.

(19) HERNANDEZ; Oscar: «Conservación: necesidad económica». Arquitectural Cuba. LA HABANA, Nº 367-68/1987, pag. 17.

(20) ESCOBAR, Mireya: «Estructuración de las zonas de viviendas». Arquitectura/Cuba. LA HABANA, N 367-68/1987, pag. 24.

(21) Sobre el tema de la vivienda en Cuba, especialmente trascendente en La Habana, resulta muy útil la consulta de SEGRE, Roberto: La vivienda en Cuba: república y revolución. LA HABANA, Ministerio de Educación, 1985.

(22) AA.VV: Transformación urbana..., pag. 125.

(23) LE RIVEREND, J: La Habana, espacio..., pag. 284.

(24) HERNANDEZ, O: «Conservación...», pag. 18.

(25) Esta situación de precariedad queda atestiguada por el artículo de MENENDEZ, José: «¿Por qué se caen los balcones?». Arquitectura/Cuba. LA HABANA, $\mathbf{N}^{\circ} 367-68 / 1987$, pp. 74/88, en el que se analiza un problema peligroso y, por desgracia, muy frecuente en numerosas viviendas de La Habana Vieja, Centro Habana, Vedado y otros barrios de la capital cubana.

(26) AA.VV: Rehabilitación de cascos históricos. GRANADA, Diputación, 1990 , pag. 29.

(27) Las palabras de Cervellati están recogidas en SEGRE, Roberto: Historia de la arquitectura y el urbanismo. Países desarrollados. Siglos XIX y XX. MADRID, IEAL, 1985, pag. 367.

(28) CERRILLOS, $M^{a}$ Luisa: «Programa de Revitalización Integral de Centros Históricos de Iberoamérica». En AA.VV: Las Ciudades del Encuentro. MEXICO, Ed. Limusa, 1992, pag. 183.

(29) GASPARINI, Graziano: «Centros históricos, patrimonio construido, recuperación y estética urbana». En SOLANO, Francisco de (coord.): Historia y futuro de la ciudad iberoamericana. MADRID, CSIC-UIMP, 1986, pag. 126. En la misma página el autor nos recuerda algo muy evidente pero a la vez revelador de las diferencias a las que he aludido: «(...) débese reconocer que es 
muy diferente vivir en el centro de París que en el centro de México, en el centro de Londres que en el de Lima o en el centro de Viena que en el de Caracas».

(30) SEGRE, Roberto (relator): América Latina en su arquitectura. MEXICO, Ed. Siglo XXI, 1975, pag. 99.

(31) CASTELLS, Manuel: Crisis urbana y cambio social. MADRID, Ed. Siglo XXI, 1981, pag. 186. El autor ofrece un análisis desde una óptica marxista de cómo los sectores populares urbanos «marginales» pueden aliarse con el proletariado y el campesinado en América Latina a través de una práctica reivindicativa cotidiana para una transformación de las injusticias derivadas de la sociedad propia del capitalismo dependiente.

(32) Son las opiniones de Mario Coyula recogidas en una entrevista de ROMERO, Nieves; BUENAVILLA, Rolando: «Mario Coyula o la ética de la ciudad». Revolución y Cultura. LA HABANA, No 4/1991, pag. 4.

(33) En ese sentido se enmarca uno de los preceptos del recientemente aprobado Código de Etica de los Cuadros del Estado Cubano que ordena «Desarrollar la disposición al diálogo y a la comunicación eficaz con el colectivo», añadiendo que «Es un elemento indispensable para el acierto de las decisiones y para la creación de un ambiente de trabajo cohesionado y participativo». Granma, 18VII-1996, pag. 5.

(34) LAPIDUS, Luis: «Patrimonio cultural y turismo». Arquitectura/Cuba. LA HABANA, $\mathrm{N}^{\circ} 370 / 1987$, pag. 4. El autor ofrece un análisis muy interesante, sugerente y profundo sobre el tema.

(35) BRANDOLINI, Sebastiano: «El realismo de la «Modificazione»». En POL, Francisco (Coord.): Arquitectura y urbanismo en las ciudades históricas. MADRID, UIMP y MOPU, 1988, pag. 24.

(36) Esta experiencia existe también en Cuba, donde se han producido numerosas intervenciones sobre centros históricos. La más conocida quizá sea el trabajo en Trinidad, pero otros muchos cascos antiguos de la isla han recibido un estudio y una actuación detalladas. Sirvan como ejemplo dos artículos publicados en el $\mathrm{N}^{\circ} 367-68$ de 1987 de la revista Arquitectura/Cuba: uno de José Rojo con el título «Ideas para inventariar un centro histórico» para el caso de Matanzas, y otro de Teresita González y Lino Delgado sobre la «Renovación del centro tradicional de Santa Clara», y otro del $\mathrm{N}^{\mathbf{0}}$ 370/1988, firmado conjuntamente por los arquitectos Héctor Ruiz, Mayra Cabrera y Teresa Lara, que se centra en la «Remodelación y reurbanización de áreas centrales de la ciudad de Cienfuegos».

(37) ROMERO, N; BUENAVILLA, R: «Mario Coyula...», pag. 11. 